\title{
Research on Distribution Vehicle Routing Optimization Based on Cloud Computing
}

\author{
Chen Keming ${ }^{1,2, *}$ \\ ${ }^{1}$ School of Business and Management, Donghua University, Shanghai 200051, China \\ ${ }^{2}$ School of Continuing Education, XinYu University, XinYu University, JiangXi, 338004, China
}

\begin{abstract}
The article analyzed the parallel programming mode of cloud computing. In order to increase solution rate of real-time optimization model, the article also proposed parallel genetic algorithm in the cloud computing environment. The article also researched on real time optimization vehicle routing problem of cold chain logistics distribution based on cloud computing and simulation. The experiment results verify the validity of the model.
\end{abstract}

Keywords: Cloud computing, Cold chain logistics, Distribution vehicle routing, Real-time optimization.

\section{INTRODUCTION}

Cloud computing is a new mode of calculation. It is the development of distributed computing, parallel computing and grid computing [1]. Cloud computing uses the Internet to integrate heterogeneous computing resource and conducts virtual pool of computing resources, and then provides users the services of computing cloud and storage cloud through the network. Cloud computing brought changes in service and made computing resources into a professional service. Cloud computing, or in simpler shorthand just "the cloud", also focuses on maximizing the effectiveness of the shared resources. Cloud resources are usually not only shared by multiple users but are also dynamically reallocated as per demand [2]. This can work for allocating resources to users. For example, a cloud computer facility that serves European users during European business hours with a specific application may reallocate the same resources to serve North American users during North America's business hours with a different application [3]. This approach should maximize the use of computing power thus reducing environmental damage as well since less power, air conditioning, rack space, etc. are required for a variety of functions [4].

Vehicles path problem is the main research problem in logistics distribution and has been research hot spots for scholars [5]. Dantzig and Ramser firstly conducted related research on VRP. In 1962, Quandt and Balinski established the most simple VRP model [6, 7]. In 1964, Wright and Clarke proposed a solution of the question of Dantzig and Ramser and improved new effective heuristic algorithm (saving algorithm). When their study was published, this made a difference on experts and scholars in the field of science, computer applications, and other subjects [8].

*Address correspondence to this author at the School of Business and Management, Donghua University, Shanghai 200051, China;

Tel: 13879068233; E-mail: 403848072@qq.com
Dynamic distribution vehicles path optimization model and design of solution algorithm is a very tricky problem [9]. From application of actual fact, when the production enterprise or customer gave their demand of goods in the cold chain logistics distribution, the team charged for distribution [10]. There are less consideration about saving cost and reducing resources waste or improving service quality. Due to the complexity of dynamic vehicles scheduling, the theory research is very hard to implement and this led to low efficiency of vehicles distribution.

The rest of the paper is organized as follows. In Section 2 , overview of cloud computing is summarized briefly. In Section 3, distribution vehicle routing problem based on cloud model is described. In Section 4, experiments are presented and the results are discussed. Finally, a conclusion is provided in Section 5.

\section{OVERVIEW OF CLOUD COMPUTING}

\subsection{Definition of Cloud Computing}

Cloud computing has two division of broad and narrow cloud computing. Broad cloud computing refers to deliver and use model about service. The service can be related to information technology, software and Internet, or it can also be service including calculation capacity. This means that calculation capacity can be used as merchandise through Internet for circulation. Narrow cloud computing refers to deliver and use model about information technology facilities. It means to obtain needed resources through more easy extended way ((hardware, platform, software and data).

There are mainly the following three representative definitions. (1) cloud computing is a service which can rapidly provide resources on demand within a short time to avoid excessive and low use of resources. (2) cloud computing is a parallel and distributed system which is constituted by the virtualized compute resources and can provide services 
dynamically according to the predetermined service level agreements of the service providers and users. (3) cloud computing is a pool of virtualized resources. The pool can be reconfigured dynamically based on load in order to achieve optimal use of it. The user and service provider predetermine service level agreements and users pay for the service in real-time.

\subsection{Feature of Cloud Computing}

Both the broad and narrow cloud computing are featured with rapid deployment of resources or access to services, pay for usage fee and availability through the Internet and other characteristics.

1) Rapid deployment of resources or access to services. The network providing resource is called "cloud". Expert network firm sets up computer memory which computing center and users can easily access with a browser via a network cable. The "cloud" is used as a data storage and application service center.

2) Extensions and use on demand. Resources in "cloud" is infinitely scalable for users and may be accessed at any time. It also can be used on demand and extended in real-time. This feature is often referred to infrastructure like water and electricity which uses information technology.

3) Pay for usage fee. In the cloud computing model, users access to resources on demand and only pay for this part.

4) Availability through the Internet. In the cloud computing model, Internet is used to be a large pool of resources. Users have the terminal equipment with basic functions and access to the other resources from the Internet.

\subsection{Type of Cloud Computing}

Cloud computing can be divided into private cloud, community cloud, public cloud and hybrid cloud from the perspective of cloud computing deployments. Private cloud is managed and operated by an organization. Community cloud is managed and operated by multiple organization with a consistent scheduling and security policies. Public cloud is maintained and managed by an organization and provides external cloud services which can be owned by the public. Hybrid cloud is a combination of two or more cloud. Cloud computing service types can be divided into infrastructure as a service (Iaas), platform as a service (Paas) and software as a service (Saas) from the perspective of cloud computing services.

1) Infrastructure as a service. The Iaas service level is the lowest service which is close to the physical hardware resources through virtualization technologies. It can provide users with the services of treatment, storage, networks, and other resources so that users can deploy the operating system and run the software.

2) Platform as a service. The Paas service is service built on the infrastructure. Users deploy the needed software environment through software tools and development languages provided by the services. Users do not need to control the underlying network, storage, operating systems and other technical issues. Underlying services is transparent to the users and this level service is a software development and runtime environment.

3) Software as a service. The Saas is the top layer. This service is a software application developed by the former two-tier service. Different users have the simple client to call the service, for example with the browser to invoke a service. User can provide the needed agreed services and application softwares according to their actual needs through the network based on length of service and time cost.

\section{DISTRIBUTION VEHICLE ROUTING PROBLEM BASED ON CLOUD MODEL}

The ultimate goal of dynamic route optimization model for cold chain logistics distribution is to get the best delivery time and distribution costs of the vehicle. But the optimization models will be different according to the different access to application information. The location and demand of each customer is fixed and the time window of customer requirements is fixed. The load volume of refrigerated car is fixed and maximum driving distance once is fixed. There are many constraints as follows: 1) Goods of each customer can only be done by a refrigerated truck and each customer can be serviced. 2) Total demand of each customer does not exceed the maximum loading capacity of the vehicle. 3) Each distribution path cannot exceed a total length of maximum travel distance of vehicle distribution. 4) Goods should be arrived within a certain time span. If we exceed the time limit, we need to give them a certain amount of fines. 5) Inside temperature and humidity will be in a certain range during transport, otherwise it will affect customer satisfaction. 6) Road is wider than the width of the vehicle.

\subsection{Delivery Time Analysis}

We can acquit the vehicle speed in the related sections of the road according to real-time traffic reports and calculate travel time of vehicle delivery, so that the vehicle can choose a short route while driving.

$T_{s}=\sum_{j=1}^{N} t_{j(j-1)}$

The variable indicates the travel time of refrigerated car from customer to customer.

\subsection{Vehicle Cost Analysis}

Vehicle distribution cost includes multiple aspects which are as follows: (1) Fixed cost. Transport vehicles require the burden of fixed costs which includes wages and loss cost of vehicle for driver and escort. Its total fixed cost is constant $\left(\mathrm{C}_{1}=f\right)$. (2) Transport cost. Vehicle speed is different in different period during the process of low temperature distribution of the products, so that the vehicle's gas mileage also has great differences. Especially in the rush hour encounter traffic congestion conditions, the vehicle's gas mileage will be 
significantly higher. Shipping cost includes the vehicle's gas mileage of vehicles, repair and maintenance costs which are dynamic and proportional to the vehicle's mileage.

$C_{2}=\sum_{i=0}^{n} \sum_{j=0}^{n} c_{i j} x_{i j}$

(3) Damage cost. Because transport load product is corrosive and easily damaged. There are so many factors which can damage the product such as temperature, humidity and oxygen concentration in cars, micro-organisms, and so on.

$C_{3}=r \sum_{j=0}^{n} \lambda_{j}\left(a_{1} t_{i j}+a_{2} \beta_{j}+a_{3} s_{i j}\right)$

(4) Vehicle energy costs. We only consider compartment refrigerated vehicle energy costs of refrigeration.

$C_{4}=\sum_{i=0}^{n} \sum_{j=0}^{n} r_{1} \times G \times t_{i j} \times x_{i j}$

(5) Penalty cost. There is a limit of time for Logistics Company to deliver goods to the customer. We optimize with soft time windows constraints method. Customers demand for goods to arrive within a certain time span. If the goods are failed to arrive on time, the logistics distribution enterprises will be given fines.

$C_{5}=\omega_{1} \sum_{j=1}^{n} \max \left[\left(\mathrm{a}_{j}-s_{j}-t_{j}\right), 0\right]+\omega_{2} \sum_{j=1}^{n} \max \left[\left(s_{j}-b_{j}\right), 0\right]$

(6) Other cost. There are time constraints during the process of delivery of the goods. So vehicular transportation path is sometimes at highway and will generate high fees.
When the vehicle is travelling in a rush at the same time, some cities will be imposed charges according to the traffic congestion.

$C_{6}=\sum_{j=1}^{m} g_{j}$

To sum up, the logistics transport route decision model is as follows:

$$
\begin{aligned}
& \operatorname{Min}\left\{W_{1} B+W_{2} C\right\} \\
& B=\mathrm{T}_{s}+\sum_{j=1}^{n} t_{j} \\
& C=C_{1}+C_{2}+C_{3}+C_{4}+C_{5}+C_{6}
\end{aligned}
$$

\section{COMPUTATIONAL RESULTS AND COMPARI- SONS}

In a real-life, real-time optimization computation of cold chain logistics vehicle path is very heavy especially in complex transport environment. The article designs coarsegrained parallel genetic algorithm for laboratory simulation at the optimization model in the cloud computing environment. Optimization model in the simulation of the process is shown in Fig. (1)

In order to verify the efficiency of genetic algorithm in the cloud computing environment, the article selects a logistic company which has a to deliver frozen fries to customers as an example. We set that refrigerator car deliver frozen fries to eight customers and customers are located in the traffic flow in the traffic area network. The requested time range is shown in Table 1 .

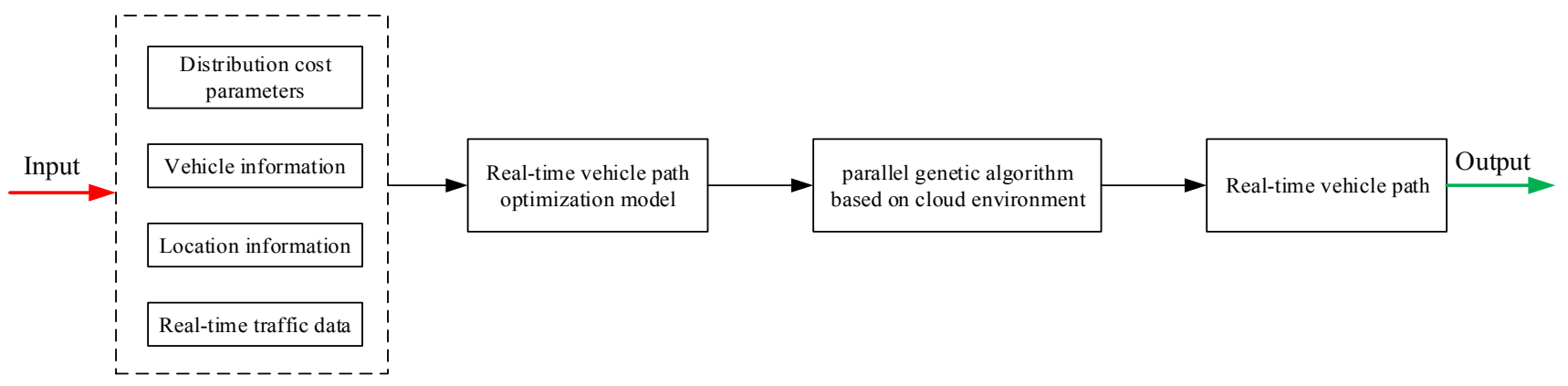

Fig. (1). The working schematic of model simulation.

Table 1. The distance of each customer.

\begin{tabular}{|c|c|c|c|c|c|c|c|c|}
\hline Note & \multicolumn{5}{|c|}{ The Distance Between Customers } & Service Window & Time & Demand \\
\hline \hline$C_{i j}$ & 0 & 1 & 2 & 3 & 4 & $(6-12)$ & 0 \\
\hline 0 & 0 & 15 & 12 & 13 & 11 & $(7-9)$ & 15 & 0.5 \\
\hline 1 & 15 & 0 & 14 & 7 & 10 & $(7-9)$ & $(7-8)$ & 15 \\
\hline 2 & 12 & 14 & 0 & 13 & 8 & $(7-8)$ & 30 & 0.65 \\
\hline 3 & 13 & 7 & 13 & 0 & 9 & $(8-9)$ & 30 & 0.23 \\
\hline 4 & 11 & 10 & 8 & 9 & 0 & 0.5 \\
\hline
\end{tabular}




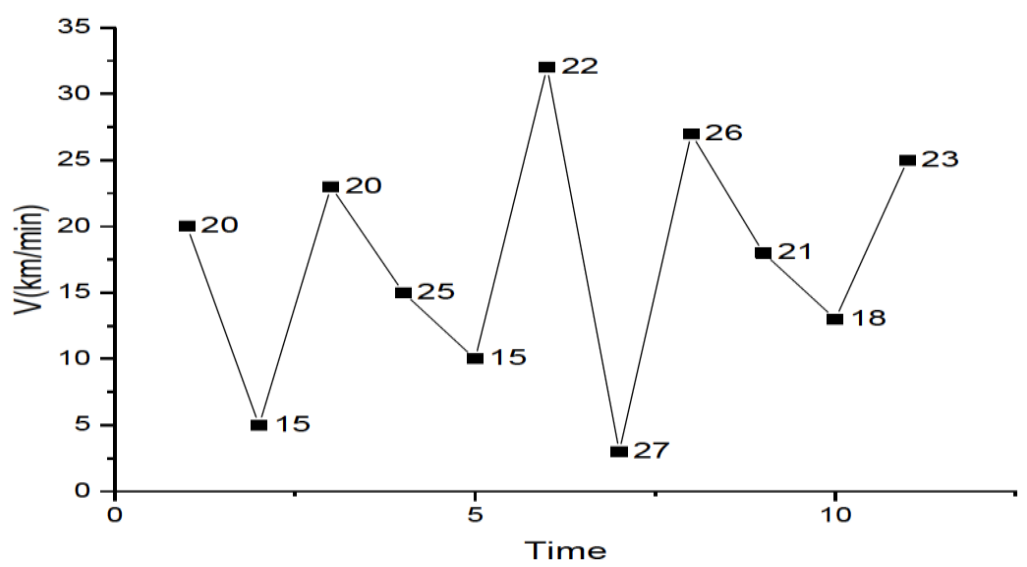

Fig. (2). The selection of transportation road traffic diagram.

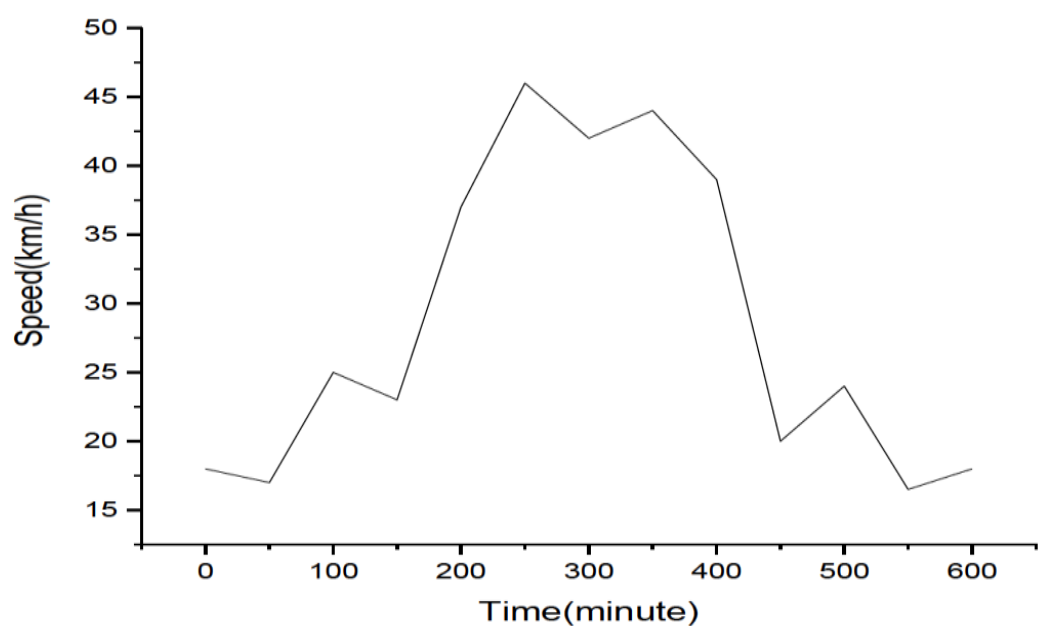

Fig. (3). The graph of vehicle speed.

The article simulates the optimization model through the design of parallel genetic algorithm and the results are shown in Figs. $(2,3)$.

\section{CONCLUSION}

The article analyzed the parallel programming mode of cloud computing and designed parallel rough grain degrees genetic algorithm. The article simulated on the optimization model and the results showed that use of cloud computing for cold chain logistics distribution vehicles path optimization of method is effective. This method can provide effective real-time optimization of path within the certain time and control cost of cold chain logistics distribution in order to improve distribution service efficiency which has the theory meaning and practical value.

It is desirable to further apply cloud computing to solving those more complex real-world optimization problems and it will be our further work.

\section{CONFLICT OF INTEREST}

The authors confirm that this article content has no conflict of interest.

\section{ACKNOWLEDGEMENTS}

This work is supported by the Key Project of Guangxi Social Sciences, China (No.gxsk201424), the Education Science fund of the Education Department of Guangxi, China (No.2014JGA268), and Guangxi Office for Education Sciences Planning, China (No.2013C108).

\section{REFERENCES}

[1] M. Armbrust, A. Fox, R. Griffith, A.D. Joseph, R. Katz, A. Konwinski, G. Lee, D. Patterson, A. Rabkin, I. Stoica and Matei Zaharia, "A view of cloud computing", Communications of the ACM, vol. 53 , no. 4 , pp. $50-58,2010$.

[2] R. Buyya, C.S. Yeo and S. Venugopal, "Market-oriented cloud computing: Vision, hype, and reality for delivering it services as computing utilities", High Performance Computing and Communications. HPCC'08. 10 ${ }^{\text {th }}$ IEEE International Conference on IEEE, pp. 5-13, 2008.

[3] M. Desrochers, J. Desrosiers, and M. Solomon, "A new optimization algorithm for the vehicle routing problem with time windows", Operations Research, vol. 40, no. 2, pp. 342-354, 1992.

[4] L.M. Gambardella, E. Taillard, and G. Agazzi, "A multiple colony system for vehicle routing problems with time windows", New Ideas in Optimization 1999.

[5] B.L. Golden, S. Raghavan and E.A. Wasil, The Vehicle Routing Problem: Latest Advances and New Challenges, Springer Science \& Business Media, Germany, 2008. 
[6] A, Juan, J. Faulin, J. Jorba, J. Caceres and J.M. Marquès, "Using parallel \& distributed computing for real-time solving of vehicle routing problems with stochastic demands", Annals of Operations Research, vol. 207, no. 1, pp. 43-65, 2013.

[7] G. Laporte, M. Gendreau, J.Y. Potvin and F. Semet, "Classical and modern heuristics for the vehicle routing problem", International Transactions in Operational Research, vol. 7, no. 4-5, pp. 285-300, 2000.
[8] P. Mell and T. Grance, "The NIST definition of cloud computing", National Institute of Standards and Technology, vol. 53, no. 6, p. 50, 2009 .

[9] D. Shin, Y. Wang, and W. Claycomb, "A policy-based decentralized authorization management framework for cloud computing", In: Proceedings of the $27^{\text {th }}$ Annual ACM Symposium on Applied Computing, ACM, pp. 465-470, 2012.

[10] Y. Song, X. He, and X. He, Study on the logistics vehicle scheduling based on cloud computing and neural network", Computer Simulation, vol. 4, p. 091, 2012.

Received: June 16, 2015

Revised: August 10, 2015

Accepted: September 19, 2015

(C) Chen Keming; Licensee Bentham Open.

This is an open access article licensed under the terms of the (https://creativecommons.org/licenses/by/4.0/legalcode), which permits unrestricted, non-commercial use, distribution and reproduction in any medium, provided the work is properly cited. 